\title{
Development of new laboratory equipment for measuring the accelerated polishing of asphalt mixes
}

\author{
Antonio Ramírez , Juan Gallego , José R. Marcobal , Carlos Blázquez
}

\begin{abstract}
A B S T R A C T
The skid resistance of pavements tends to decrease over time, resulting in greater risks for drivers. Currently, skid resistance and macrotexture values can only be determined for existing pavements. It would be of interest to be able to predict the evolution of the skid resistance of an asphalt mixture before its installation as a highway wearing course. This paper summarizes the experience gained and the results obtained during the development of a test procedure which has been applied in the laboratory to measure the evolution of the skid resistance of hot mix asphalts through a modified version of an accelerated polishing machine which is normally used to determine the polished stone value of aggregates.
\end{abstract}

\section{Introduction}

Skid resistance is the term commonly given to the friction generated between vehicle tires and wearing course of a pavement [1]. It is one of the characteristics which most significantly affects the safety of a pavement and it has serious repercussions on the reduction of accidents, especially in the event of rain or wet surfaces [2-6]. However, due to traffic and other factors, skid resistance decreases over time [7-10].

Because of this, the measurement of skid resistance has become a basic tool for highway network management [11]. Nowadays, it is still of great importance to develop standardized procedures to quantify the skid resistance of a pavement during the formulation of the asphalt in the laboratory [12], as well as to predict the evolution of this important property after the pavement has been constructed. Currently, skid resistance and macrotexture values can only be determined for existing pavements. It is merely assumed a priori that pavements will exhibit adequate values for these properties, especially if they are manufactured within specific grading parameters, using aggregates resistant to polishing, and installed according to the specifications of applicable standards [13].
In not a few cases, however, despite having rigorously followed the requirements of the current standards, the macrotexture and skid resistance of the resulting pavement do not meet the specifications, requiring the contractor, at best, to pay a fine or, at worst, to remove and reinstall a new wearing course, with which he may have the same problem.

It is clearly of great importance, then, to develop a testing procedure capable of determining the macrotexture and skid resistance values of a mixture in the laboratory before it is manufactured and laid down, and which can also estimate the evolution of these properties over time [9,11-14].

The following sections describe the new piece of laboratory equipment created for this purpose as well as the first results obtained.

\section{Design and development of testing equipment}

\subsection{Initial approach}

From the outset, the purpose of this study was to develop a testing procedure that would be as simple as possible and which would not require laboratory personnel to receive much, if any, additional training. The new machine created for this study is therefore based on commonly used laboratory equipment.

The development of the new testing device began with the machine used to determine the polished stone value (PSV) of 
a

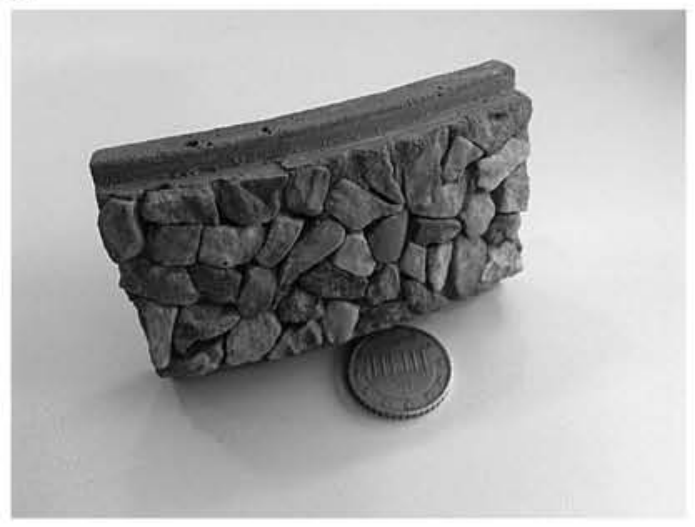

b

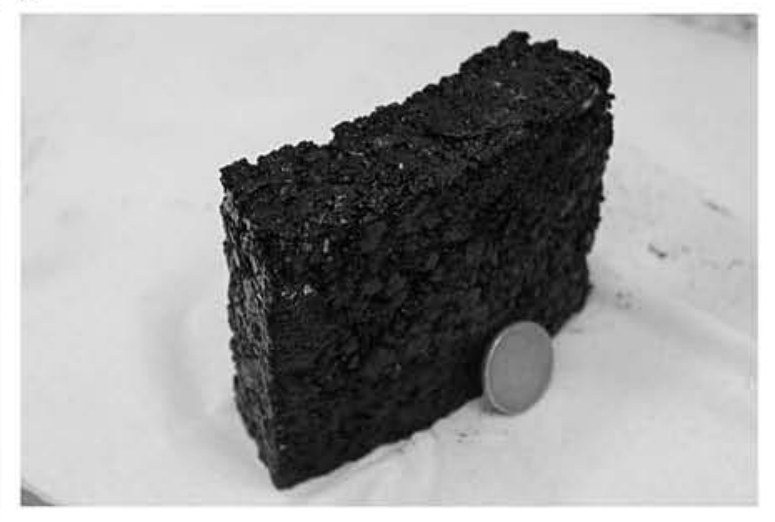

Fig. 1. (a) Aggregate specimen. (b) Asphalt specimen.

aggregates described in EN 1097-8 (Tests for mechanical and physical properties of aggregates. Part 8: determination of the polished stone value). The PSV is directly related to the tendency of an aggregate to lose its roughness or initial microtexture due to the polishing effect of tires [12]. The importance of the PSV for tire-pavement friction had already been recognized by Knill in 1960 [15].

In order to determine their PSV, the aggregates are placed in a curved mold and cemented with a resin mortar (Fig. 1a). The specimens are then placed on a testing wheel, or road wheel, along with specimens of a control aggregate; they are then subjected to polishing cycles using a loaded rubber tire, water, and two abrasives which are applied sequentially, each for three hours. After the polishing is complete, the skid resistance of the aggregate is measured with the British Pendulum Tester to obtain the PSV, as outlined in NLT-174/93 (Accelerated polishing of aggregates).

\subsection{Adaptation of the accelerated polishing machine}

In order to determine the PSV of bituminous mixtures instead of aggregates, it was necessary to make some modifications to the original road wheel, its lateral plates and the axle, as well as to increase the capacity of the motor. Modifications to other parts of the machine were not required.

The original polishing machine had a road wheel to which 14 aggregate samples $-90.6 \mathrm{~mm}$ in length, $44.5 \mathrm{~mm}$ in width, and $12.5 \mathrm{~mm}$ thick (Fig. 1a) - could be fixed. As it was not possible to manufacture asphalt specimens with these dimensions, the original testing equipment needed to be reconfigured.

The specimens of the bituminous mixture were manufactured with the same curvature as that of the aggregates, so that the polishing process would be similar. The asphalt samples were $30 \mathrm{~mm}$ thick and $82 \mathrm{~mm}$ wide (Fig. 1b), as this would guarantee sufficient compaction in the mold and a density and void content as similar as possible to those of the job mix formula. The tools and compaction procedures used to prepare the samples are described in the following sections.

The road wheel was modified to have an interior diameter of $350 \mathrm{~mm}$ so that the external diameter - the wheel plus the specimens - would be the same as on the original machine $(410 \mathrm{~mm})$. With this configuration, 12 specimens of the bituminous mixture with the above-mentioned dimensions could be attached to the wheel. The new lateral plates feature a continuous rim to support the samples during polishing. The rim covers $18 \mathrm{~mm}$ of the specimens on each side, leaving an area $46 \mathrm{~mm}$ wide for polishing (Fig. 2).

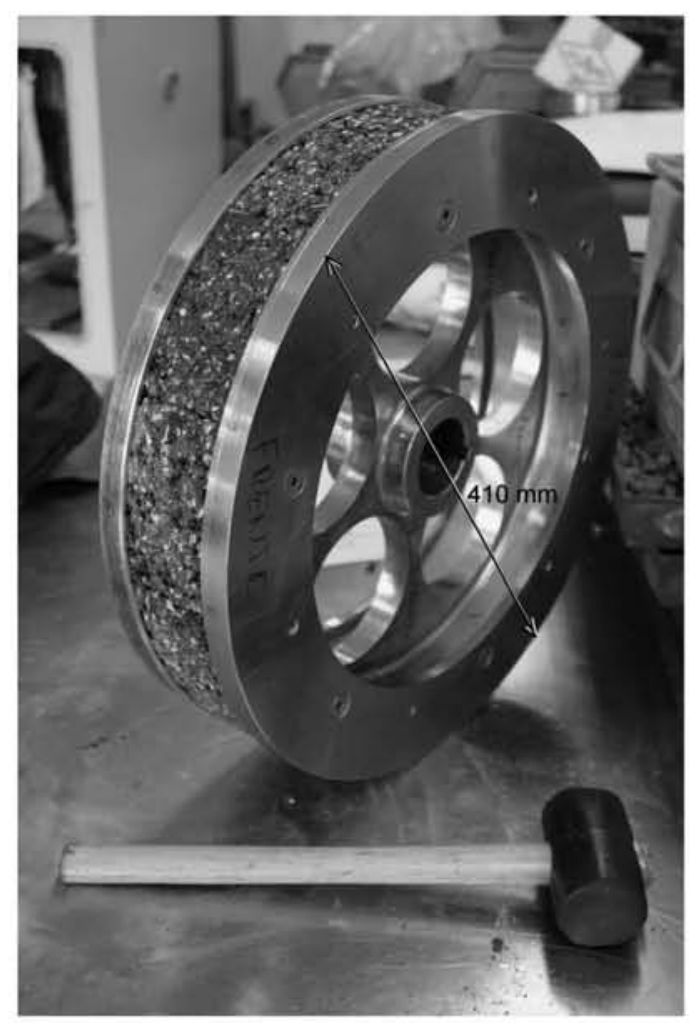

Fig. 2. New road wheel with specimens of the bituminous mixture.

\subsection{Procedure for manufacturing specimens of the asphalt mix}

The first step was to design a compaction method and the necessary accessories with which to construct the curved specimens of the bituminous mixtures. As can be seen in Fig. 1b, each specimen had an exposed convex surface and a concave surface which rested on the road wheel of the adapted polishing machine.

The compaction procedure needed to guarantee density, void content, and macrotexture for the laboratory specimens representative of field values of the same asphalt [16]. This was not possible with samples of the dimensions required when determining the PSV of aggregates. Therefore, specimens were manufactured which were $82 \mathrm{~mm}$ wide, $30 \mathrm{~mm}$ thick, $107.3 \mathrm{~mm}$ long on the external face and $91.6 \mathrm{~mm}$ on the internal face, with the aim of achieving the proper density, void content, and macrotexture for a mixture with a maximum aggregate size of $11.2 \mathrm{~mm}$. Molds were then prepared for the preparation of specimens with these dimensions. 


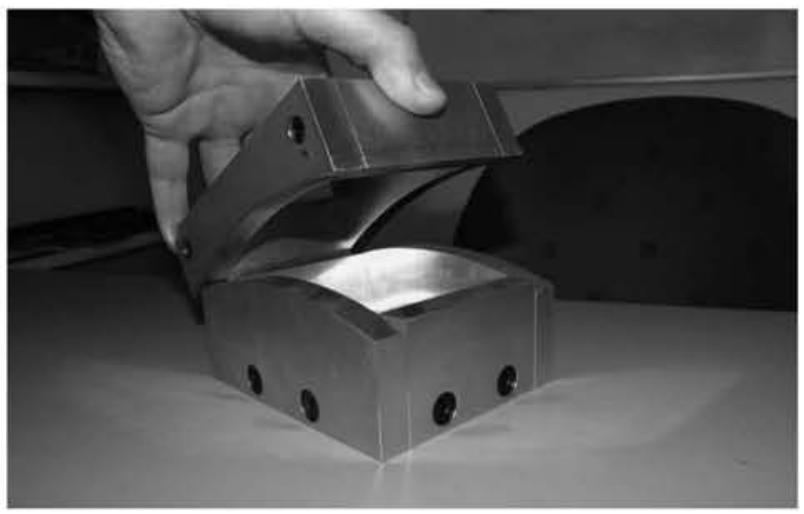

Fig. 3. Detail of mold with collar for preparation of samples.

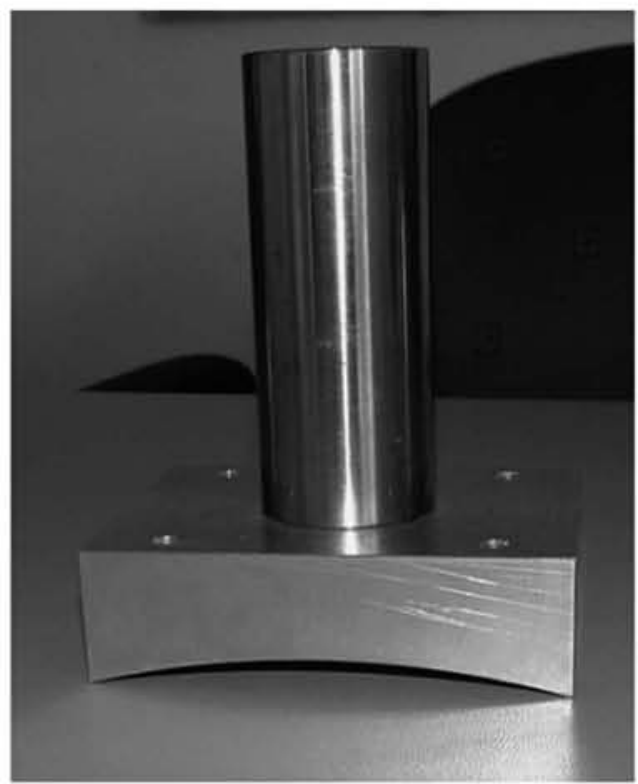

Fig. 4. Compaction tool.

The molds were constructed with thick walls in order to maintain the temperature during compaction. The molds consisted of detachable pieces which enabled the removal of compacted specimens without damaging them and ensured the correct positioning of the mold in the press during compaction. Furthermore, a collar for the mold was designed and constructed, allowing the necessary material for compaction to be added before applying the load and preventing the loss of any of the mixture through displacement during the compaction process (Fig. 3).

Before beginning the compaction process, the tools were preheated to the optimal temperature in ovens with the aim of maintaining the temperature of the mixture during compaction and avoiding problems associated with a lack of density. The compaction temperature of the mixtures prepared for the experiment was $165^{\circ} \mathrm{C}$.

For the application of the load, a concave compaction tool was manufactured (Fig. 4). This tool, preheated to the compaction temperature, was placed directly on top of the material in the mold and the load was applied at a rate of $800 \mathrm{~N} / \mathrm{s}$ until the thickness of the sample reached $30 \mathrm{~mm}$, without surpassing $200 \mathrm{kN}$ at any point in the process.

\subsection{Measurement of the skid resistance of the bituminous mixtures}

Among the existing equipment for measuring skid resistance, one of the most commonly used is the British Pendulum Tester

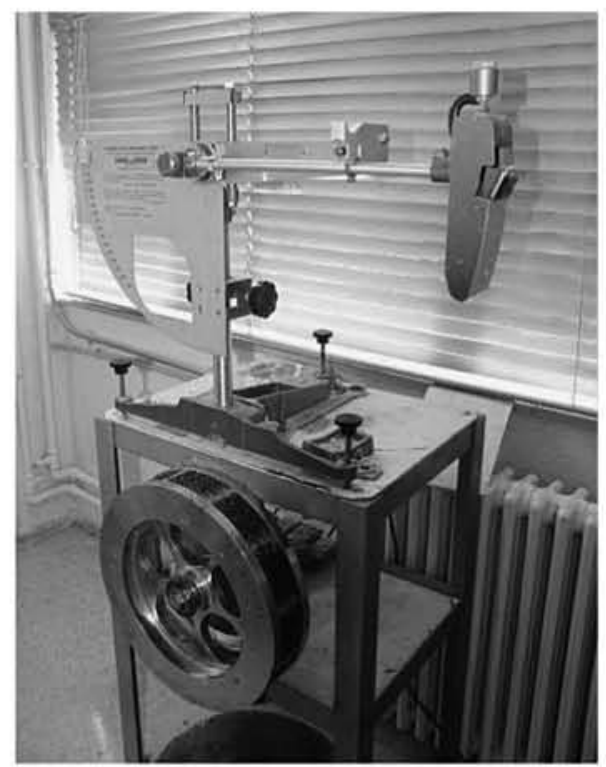

Fig. 5. BPT ready to measure the skid resistance of the asphalt specimens.

(BPT); in Spain, this tool is referred to in the standard procedures NLT-175/98 (Measuring skid resistance with British Pendulum Tester) and EN 1097-8 (Determination of the polish stone value). The BPT has been widely used since the 1960 s to measure skid resistance and can be used in the laboratory and in the field [4].

The specimens of the asphalt, manufactured according to the procedure outlined above, were placed on the new road wheel and subjected to a polishing process similar to that used for aggregates when determining their PSV according to EN 1097-8. The evolution of the skid resistance of the samples was measured hourly using the BPT. This device tests skid resistance by measuring the loss of energy of a pendulum of known characteristics, fitted with a rubber slider, when the slider comes into contact with a surface over a given distance at a given pressure. This energy loss is converted into the coefficient of friction, or skid resistance, using a scale which marks the supplementary angle of the oscillation of the pendulum [1].

As the slip speed is quite low - it comes to around $10 \mathrm{~km} / \mathrm{h} \mathrm{-,}$ the results of the skid resistance test are influenced above all by the microtexture of the pavement; indeed, the test provides an indirect means of characterizing microtexture [2,17]. Fig. 5 shows the BPT ready to measure the skid resistance of the specimens of the bituminous mixture mounted on the new road wheel adapted for this test.

In the laboratory tests outlined in EN 1097-8 (Determination of the polish stone value), the PSV of an aggregate is obtained by correcting the value obtained empirically using the following equation:

$\mathrm{PSV}=S+52.5-C$

where:

$S=$ the average value of the skid resistance of 4 aggregate specimens, measured on the pendulum scale.

$C=$ the average value of the skid resistance of 4 specimens of control aggregate (PSV between 49.5 and 55.5), measured on the pendulum scale.

However, in this study, as no "control mixture" was yet available, the values used for the skid resistance value (Table 4) are those obtained directly using the pendulum scale without any 
subsequent correction. Work is currently being undertaken to establish a control asphalt mixture.

\section{Mixtures tested with new equipment}

\subsection{Materials}

A BBTM 11B mixture was manufactured, as this is a type of gapgraded asphalt concrete used in Spain for thin layers on highways with heavy traffic. BBTM 11B mixes are usually installed with thicknesses of between 2.5 and $3 \mathrm{~cm}$ and consist of $75-85 \%$ course aggregate (larger than $2.0 \mathrm{~mm}$ ), 15-25\% fine aggregate, 5-8\% filler, and approximately $5 \%$ bitumen.

The characterization of the materials, as well as of the mixture itself, was based on European Committee for Standardization (EN) standards and, in some cases, the Spanish Technical Norms (NLT) for highway testing, outlined by the Centre for Studies and Experimentation of the Ministry of Public Works (CEDEX).

The bitumen used to manufacture the mixtures was a PMB 45/ 80-65, modified with SBR polymers, which meets all of the specifications outlined in Article 212 of Spanish standard PG-3 (General Technical Specifications for Roads and Bridges).

The aggregates used for the experiment were a $0 / 4 \mathrm{~mm}$ silica sand and a $6 / 12 \mathrm{~mm}$ porphyry gravel. The filler used in the manufacture of the mixtures was a calcium carbonate. The main characteristics of the aggregates are listed in Table 1. The PSV of the coarse aggregate was 57.5.

Based on the granulometric fractions of the different aggregates used for the mixture, several estimates were made to determine the grading curve of the combined aggregates, which were then compared to the parameters provided by PG-3 for BBTM 11B mixes.

The grading curve was obtained using the proportions of aggregates shown in Table 2. As can be seen, the aggregates fell within the parameters stipulated for a BBTM 11B mixture.

The Marshall Test was used to determine the optimum binder content for the mixture (EN 12697-34), resulting in a value of $5.35 \%$ of total aggregate weight, an apparent density of $2.04 \mathrm{~g} / \mathrm{cm}^{3}$ according to EN 12697-6, a maximum density of $2.53 \mathrm{~g} / \mathrm{cm}^{3}$ according to EN 12697-5, and a percentage of air voids of $19 \%$ according to EN 12697-8.

Using this optimum binder content, the water sensitivity test was conducted, as described in EN 12697-12. The wet and dry indirect tensile strength values were $1.31 \mathrm{MPa}$ and $1.45 \mathrm{MPa}$, respectively, and the retained strength was $90 \%$. The wheel-tracking test (EN 12697-22) resulted in an average creep slope of 0.064 ( $\mathrm{mm} / 1000$ loading cycles) between 5000 and 10,000 cycles and an average rut depth of $2.2 \%$. Based on these values, and according to Article 543 of PG-3, this type of mixture meets the requirements for use in constructing the wearing courses of highways submitted to T00 traffic (an average daily intensity of heavy vehicles greater or equal than 4000). It is, in fact, the main mixture used to construct a segment of the A1 motorway connecting Madrid to the north of Spain.

This asphalt mix was used to measure the skid resistance with the modified accelerated polishing machine, the results of which will be discussed in the following sections. The mixture was produced using aggregates and bitumen provided by the company which constructed the section of the A1 motorway mentioned above.

\subsection{Preparation of test specimens}

Once the job mix formula had been determined, the specimens of mixture were manufactured for subsequent polishing, according to the methods and compaction procedure described above, using materials from the construction of the A1 motorway.

In order to ensure that the degree of compaction was sufficient, the density and void content of each sample were calculated. The current standard for Spain (Article 543 of PG-3) states that for BBTM 11B mixtures the void content must not differ more than $\pm 2 \%$ from that of the job mix formula, which in this case was $19 \%$. The void content of the samples was determined based on the maximum density of the mixture (EN 12697-5), which was $2.53 \mathrm{~g} /$ $\mathrm{cm}^{3}$, and on the apparent density, volumetric procedure (EN 12697-6), which varied slightly from one sample to another. As the specimens were curved, their volume was calculated based on measurements taken with a caliper at different points along the specimen: six measurements to calculate the thickness and three for the width. The average void content obtained with this procedure was $18.96 \%$, practically identical to the job mix formula; the values for each of the specimens fell within the required range of $17-21 \%$.

As previously mentioned, it was necessary for the compaction procedure to reproduce the macrotexture of an actual pavement in the laboratory. For this reason, the macrotexture of each sample was measured after compaction by means of a modified sand patch test (EN 13036-1), in which $5000 \mathrm{~mm}^{3}$ of sand were spread over the surface of the specimen with the spreading tool defined by the standard. The voids on the surface of the specimen were filled until

Table 1

Test results for aggregates used to manufacture the bituminous mixtures.

\begin{tabular}{|c|c|c|c|}
\hline \multicolumn{2}{|l|}{ Test } & \multicolumn{2}{|l|}{ Result } \\
\hline & & $6 / 12$ porphyry & $0-4$ silica \\
\hline \multirow[t]{9}{*}{ Grain size (EN 933-1) } & Sieve & $\%$ of material passing & $\%$ of material passing \\
\hline & 16 & 100 & \\
\hline & 12.5 & 99.7 & \\
\hline & 8 & 37.25 & 100 \\
\hline & 4 & 1.22 & 99.75 \\
\hline & 2 & 0.66 & 76.52 \\
\hline & 0.5 & & 36.31 \\
\hline & 0.125 & & 16.88 \\
\hline & 0.063 & 0.15 & 12.66 \\
\hline \multicolumn{2}{|l|}{ Sand equivalent according to EN 933-8 } & - & 47 \\
\hline \multicolumn{2}{|c|}{ Percentage of crushed surfaces according to EN 933-5 } & $100 \%$ & - \\
\hline \multicolumn{2}{|c|}{ Shape of coarse aggregate (Flakiness Index) according to EN 933-3 } & $6.69 \%$ & - \\
\hline \multicolumn{2}{|c|}{ Resistance to fragmentation of coarse aggregate (Los Angeles Abrasion Coefficient) according to EN 1097-2 } & 10.5 & - \\
\hline \multicolumn{2}{|c|}{ Resistance of coarse aggregate to polishing (Polished Stone Value, PSV) according to EN 1097-2 } & 57.5 & - \\
\hline \multicolumn{2}{|c|}{ Cleanness of coarse aggregate 146130 Annex C } & $0.4 \%$ & - \\
\hline \multirow[t]{2}{*}{ Relative density and absorption (EN 1097-6) } & Apparent Relative Density & $2.71 \mathrm{~g} / \mathrm{cm}^{3}$ & $2.558 \mathrm{~g} / \mathrm{cm}^{3}$ \\
\hline & Absorption Coefficient & $0.43 \%$ & $0.94 \%$ \\
\hline
\end{tabular}


Table 2

Grading curve of the bituminous mixture.

\begin{tabular}{|c|c|c|c|}
\hline \multicolumn{4}{|c|}{ Proportioning of aggregates } \\
\hline Fraction (mm) & $6 / 12$ & $0 / 4$ & Filler added \\
\hline Composition & $78 \%$ porphyry & $17.3 \%$ silica & $4.7 \%$ calcium carbonate \\
\hline \multicolumn{4}{|c|}{ Gradation band and laboratory curve } \\
\hline SIEVE $(\mathrm{mm})$ & \multicolumn{2}{|c|}{ BBTM 11 B gradation band (\% passing) } & Grading curve of the specimens (\% passing) \\
\hline 16 & \multicolumn{2}{|l|}{100} & 100 \\
\hline 11.2 & \multicolumn{2}{|l|}{$90-100$} & 99.5 \\
\hline 8 & \multicolumn{2}{|l|}{$60-80$} & 73.7 \\
\hline 4 & \multicolumn{2}{|l|}{$17-27$} & 23.2 \\
\hline 2 & \multicolumn{2}{|l|}{$15-25$} & 17.6 \\
\hline 0.5 & \multicolumn{2}{|l|}{$8-16$} & 10.7 \\
\hline 0.063 & \multicolumn{2}{|l|}{ 4-6 } & 5.7 \\
\hline
\end{tabular}

Table 3

Characteristics of the compacted specimens.

\begin{tabular}{|c|c|c|c|c|c|c|c|}
\hline \multicolumn{8}{|c|}{ Compacted specimens } \\
\hline Specimen \# & Thickness (cm) & Width (cm) & Volume $\left(\mathrm{cm}^{3}\right)$ & Weight (g) & Volumetric density $\left(\mathrm{g} / \mathrm{cm}^{3}\right)$ & Air voids (\%) & Initial macrotexture ( $\mathrm{mm}$ ) \\
\hline 1 & 2.91 & 8.11 & 234 & 489 & 2.092 & 17.30 & 0.99 \\
\hline 2 & 2.90 & 8.16 & 234 & 483 & 2.061 & 18.53 & 0.84 \\
\hline 3 & 2.91 & 8.25 & 238 & 489 & 2.052 & 18.88 & 0.82 \\
\hline 4 & 2.95 & 8.10 & 237 & 484 & 2.039 & 19.40 & 0.91 \\
\hline 5 & 2.98 & 8.12 & 241 & 485 & 2.013 & 20.42 & 0.90 \\
\hline 6 & 2.96 & 8.11 & 238 & 487 & 2.045 & 19.17 & 0.85 \\
\hline 7 & 2.92 & 8.09 & 234 & 481 & 2.052 & 18.90 & 0.84 \\
\hline 8 & 2.87 & 8.34 & 238 & 492 & 2.071 & 18.14 & 0.81 \\
\hline 9 & 2.91 & 8.22 & 237 & 482 & 2.033 & 19.63 & 0.92 \\
\hline 10 & 2.87 & 8.24 & 235 & 483 & 2.056 & 18.73 & 0.74 \\
\hline 11 & 2.91 & 8.23 & 238 & 483 & 2.028 & 19.84 & 0.80 \\
\hline 12 & 2.92 & 8.11 & 235 & 484 & 2.061 & 18.55 & 1.00 \\
\hline Maximum & 2.98 & 8.34 & 240.90 & 492.00 & 2.092 & 20.42 & 1.00 \\
\hline Minimum & 2.87 & 8.09 & 233.72 & 481.00 & 2.013 & 17.30 & 0.74 \\
\hline Average & 2.92 & 8.17 & 236.64 & 485.17 & 2.050 & 18.96 & 0.87 \\
\hline Standard deviation & 0.032 & 0.080 & 2.169 & 3.353 & 0.021 & 0.823 & 0.077 \\
\hline
\end{tabular}

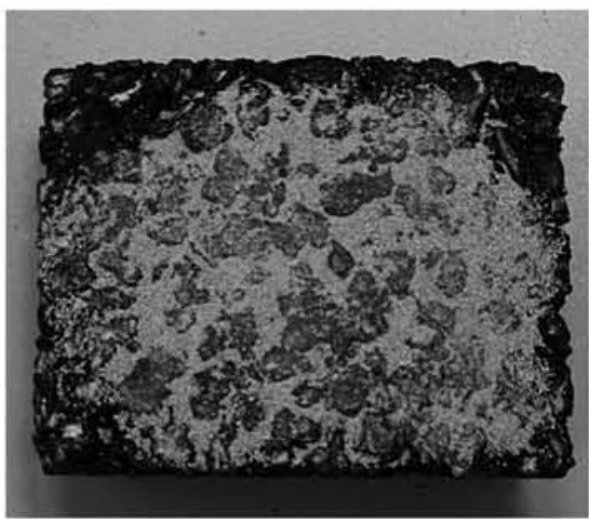

Fig. 6. Macrotexture of specimen 10.

the sand reached the level of the peaks of the aggregate particles. Based on digital measurements of the surface area of the resulting patch, the average depth of the sand patch was calculated, dividing the volume of the sand by the surface area of the patch. The average value was $0.87 \mathrm{~mm}$, quite far from the $1.5 \mathrm{~mm}$ minimum required by Article 543 of PG-3 for this type of mixture, and from the $2.09 \mathrm{~mm}$ value obtained for the asphalt with the same job mix formula laid down on the A1 motorway manufactured. Test samples similar to those used for the wheel-tracking test were then manufactured according to EN 12697-33:2006+ A1 (Bituminous mixtures - Test methods for hot mix asphalt - Part 33: Specimen prepared by roller

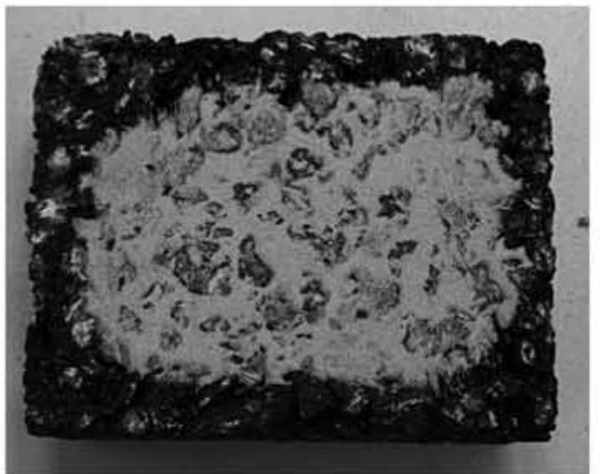

Fig. 7. Macrotexture of specimen 12.

compactor) to see if a different macrotexture could be produced using a different compaction system [18]. This resulted in a value of $2.5 \mathrm{~mm}$ - much closer to the macrotexture of the actual pavement.

Table 3 presents the results of the macrotexture test for each specimen. The results display dispersion with values varying between 0.74 and $1 \mathrm{~mm}$. The average value is $0.87 \mathrm{~mm}$ and the standard variation is 0.077 , which shows that not only did the specimens exhibit a heterogeneous macrotexture, but the results also were substantially lower than those obtained using compaction processes more similar to those normally used to construct pavements. 
The following images show that the area covered by the sand patch is much larger in the case of specimen 10 than for specimen 12 , meaning that the macrotexture of the latter was greater ( $1 \mathrm{~mm}$, compared to $0.74 \mathrm{~mm}$ ) (Figs. 6 and 7).

\subsection{Polished stone value of the mixtures}

Once these measurements had been taken, the 12 specimens were placed on the road wheel and, before beginning the polishing process, the PSV of each specimen was determined using the BPT according to NLT-174/93 (Accelerated polishing of aggregates). During the assembly of the wheel, as a precaution, a series of small rubber strips were placed beneath the concave face of several of the specimens in an attempt to eliminate the differences in thickness between the specimens (Table 3 ) which were responsible for the small ridges between contiguous specimens in a preliminary experiment that showed early failure.

In fact, the polishing wheel broke the specimens on the road wheel after a few minutes due to the discontinuities between segments. For this reason, in addition to the application of the rubber strips, the joints between the samples were sealed with fine sand and a low viscosity epoxy resin, to avoid affecting the tested surface (Fig. 8).

The asphalt specimens were then polished according to the procedures outlined in EN 1097-8 for the determination of the polished stone values of aggregates, taking note of the skid resistance values measured hourly with the BPT (Table 4).

As can be observed in Table 4, the six-hours results for the skid resistance are not greatly dispersed, varying between a minimum

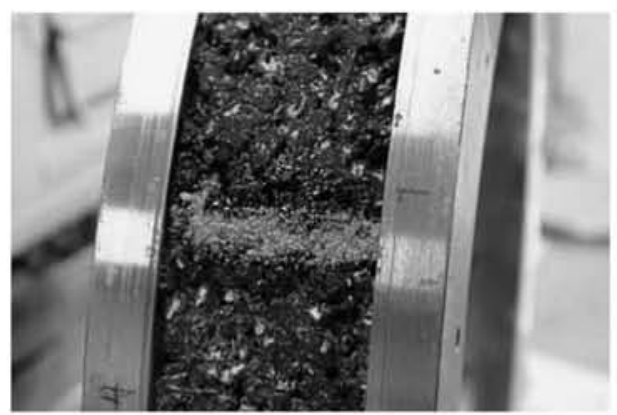

Fig. 8. Detail of the protective seal placed at the joints between the specimens. of 0.57 and a maximum of 0.63 , with an average value of 0.6 and a standard deviation of 0.016 . This average six-hours result is called polished asphalt mix value (PAMV).

Fig. 9 shows the evolution of the average skid resistance value over time. The results are in accordance with the findings of previous studies of the evolution of the skid resistance of a pavement over time. These studies concluded that after the construction of a wearing course, there can be an increase in the skid resistance until the film of binder, covering the surface of the aggregates that comes into contact with the tires, disappears and the microtexture of the aggregate is exposed. The skid resistance then begins to decrease over time in proportion to the polishing of the aggregates due to the traffic [13].

\section{Conclusions}

A new testing procedure has been developed which allows the evolution of the skid resistance of an asphalt mix to be measured in the laboratory, using a British Pendulum Tester, by subjecting the mixture to a polishing process similar to that used to determine the polished stone value of aggregates.

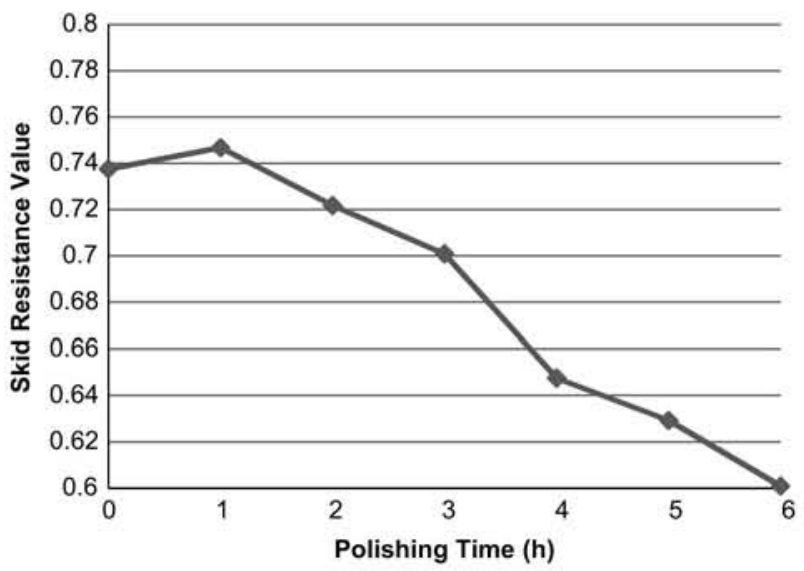

Fig. 9. Evolution of skid resistance measured with BPT of asphalt polished according to modifications of EN 1097-8. The six-hours result is called polished asphalt mix value (PAMV).

Table 4

Evolution of skid resistance values measured with BPT.

\begin{tabular}{|c|c|c|c|c|c|c|c|c|}
\hline \multicolumn{9}{|c|}{ Skid resistance value. BBTM 11B mixture } \\
\hline \multirow{2}{*}{ Specimen } & \multirow{2}{*}{ Macrotexture (mm) } & \multicolumn{7}{|c|}{ Time (h) } \\
\hline & & 0 & 1 & 2 & 3 & 4 & 5 & 6 \\
\hline 1 & 0.99 & 0.64 & 0.71 & 0.67 & 0.74 & 0.60 & 0.65 & 0.59 \\
\hline 2 & 0.84 & 0.74 & 0.75 & 0.73 & 0.70 & 0.60 & 0.65 & 0.57 \\
\hline 3 & 0.82 & 0.75 & 0.77 & 0.75 & 0.74 & 0.70 & 0.65 & 0.59 \\
\hline 4 & 0.91 & 0.75 & 0.75 & 0.75 & 0.74 & 0.70 & 0.58 & 0.60 \\
\hline 5 & 0.90 & 0.77 & 0.74 & 0.73 & 0.72 & 0.70 & 0.55 & 0.59 \\
\hline 6 & 0.85 & 0.80 & 0.74 & 0.67 & 0.65 & 0.62 & 0.65 & 0.61 \\
\hline 7 & 0.84 & 0.75 & 0.74 & 0.70 & 0.65 & 0.65 & 0.67 & 0.59 \\
\hline 8 & 0.81 & 0.67 & 0.72 & 0.74 & 0.69 & 0.65 & 0.60 & 0.60 \\
\hline 9 & 0.92 & 0.77 & 0.77 & 0.75 & 0.70 & 0.65 & 0.65 & 0.62 \\
\hline 10 & 0.74 & 0.67 & 0.75 & 0.74 & 0.67 & 0.65 & 0.60 & 0.61 \\
\hline 11 & 0.80 & 0.77 & 0.75 & 0.70 & 0.70 & 0.60 & 0.65 & 0.61 \\
\hline 12 & 1.00 & 0.77 & 0.77 & 0.73 & 0.71 & 0.65 & 0.65 & 0.63 \\
\hline Maximum & 1.00 & 0.80 & 0.77 & 0.75 & 0.74 & 0.70 & 0.67 & 0.63 \\
\hline Minimum & 0.74 & 0.64 & 0.71 & 0.67 & 0.65 & 0.60 & 0.55 & 0.57 \\
\hline Average & 0.87 & 0.74 & 0.75 & 0.72 & 0.70 & 0.65 & 0.63 & 0.60 \\
\hline Standard deviation & 0.077 & 0.050 & 0.019 & 0.029 & 0.032 & 0.038 & 0.037 & 0.016 \\
\hline
\end{tabular}


The results are in accordance with the findings of previous studies of the evolution of the skid resistance of a pavement over time, which concluded that after the construction of a wearing course, there can be an increase in the skid resistance until the film of binder, covering the surface of the aggregates that comes into contact with the tires, disappears and the microtexture of the aggregate is exposed. The skid resistance then begins to decrease over time in proportion to the polishing of the aggregates due to the traffic.

A compaction process was developed in order to prepare laboratory samples which reproduce the density and void content obtained in the field.

However, the required macrotexture was not representative of real scale application of the gap-graded mixture manufactured for the test. The macrotexture of all the specimens was below than that of the actual pavement with the same job-mix formula.

It is therefore necessary to develop new lines of research which attempt to solve this problem. Once this improved compaction procedure has been developed, comparative studies should be conducted in order to develop prediction models for the skid resistance of bituminous mixtures based on this test and the evolution of the skid resistance of in service roads.

\section{Acknowledgments}

This study is part of a research project partially financed by the Centre for the Development of Industrial Technological of the Ministry of Economy and Competitiveness (File number IDI-20111670) and has counted on the participation of SACYR CONCESIONES S.L., SACYR CONSTRUCCIÓN S.A. and PROETI S.A., as well as the Department of Civil Engineering: Transport of the Technical University of Madrid.

The authors would like to extend their appreciation to colleagues from the ESM Research Center (Madrid) and recognize their contribution to the laboratory works.

\section{References}

Austroads, Review of Skid Resistance and Measurement Methods (Publication no AP-T177-11), Austroads, Sydney, Australia, 2011.

J.J. Henry, Evaluation of Pavement Friction Characteristics (Synthesis of Highway Practice) National Cooperative Highway Research Program, National Academy Press, National Research Council (U.S.). Transportation Research Board, Washington D.C., 2000.
M. Ibrahim, Evaluating skid resistance of different asphalt concrete mixes, Build Environ. 42 (2005) 325-329. http://dx.doi.org/10.1016/j.buildenv.2005.08.020.

D.J. Wilson (Doctoral thesis), An Analysis of the Seasonal and Short-Term Variation of Road Pavement Skid Resistance, The University of Auckland. Auckland, New Zealand, 2006.

K. Malal, I. Artamendi, T. Scarpas, Long Term skid resistance of asphalt surfacing: correlation between Wehner-Schulze friction values and the mineralogical composition of the aggregates, Wear 303 (2013) 235-243. http://dx.doi.org/10.1016/j.wear.2013.03.022.

M. Ech, S. Yotte, S. Morel, D. Breysse, B. Pouteau, Qualification of wearing course material surface evolution after durability test, Constr. Build. Mater. 35 (2012) 313-320. http://dx.doi.org/10.1016/j.conbuildmat.2012.02.081.

K. Malal, J. Piau, T. Do Winh, On the study of polishing of road surface under traffic load, J. Transp. Eng.-ASCE 136 (1) (2010) 45-51. http://dx.doi.org 10.1061/(ASCE)0733-947X(2010)136:1(45).

B.D. Prowell, H. Xie, A.L, Cooley, R.B. Powell, D. Hanson, Relationships between pavement friction and material properties at NCAT test track, in: Proceedings of the 82nd Annual Meeting of the Transportation Research Board, Washington, DC, 2003.

M.-T. Do, Z. Tang. M. Kane, F.de Larrard, Evolution of road-surface skidresistance and texture due to polishing, Wear 266 (2009) 574-577. http: //dx.doi.org/10.1016/j.wear.2008.04,060.

H. Wang, Z. Wang, Evaluation of pavement surface friction subject to various pavement preservation treatments, Constr. Build. Mater. 48 (2013) 194-202. http://dx.doi.org/10.1016/j.conbuildmat.2013.06.048.

W.T. Vollor, I.D. Hanson, Development of Laboratory Procedure for Measuring Friction of HMA Mixtures- Phase I (Report 06-06 NCAT), . 2006.

M. Del Val, The Skid Resistance of Road Pavements, Spanish Association of Asphalt Mix Manufacturers (ASEFMA), Madrid, 2010.

R.S. McDaniel, B.J. Coree, Identification of Laboratory Techniques to Optimize Superpave HMA Surface Friction Characteristics (Phase I: Final Report (No. SQDH 2003-6, HL 2003-19), North Central Superpave Centre, Purdue University, Indiana, USA, 2003.

M.-T. Do, T. Zhenzhong, K. Malal, F. Larrard, Pavement polishing-development of a dedicated laboratory test and its correlation with road results, Wear 263 (2007) 36-42. http://dx.doi.org/10.1016/j.wear.2006.12.086.

C.D. Knill, Petrographical aspects of the polishing of natural roadstones, J. Appl. Chem. 10 (2010) 1-56. http://dx.doi.org/10.1002/jctb.5010100108.

G. Boscaino, B. Celauro, C. Celauro, A. Arnadore, Evaluation of the laboratory prediction of surface properties of bituminous mixtures, Constr. Build. Mater. 23 (2009) 943-952. http://dx.doi.org/10.1016/j.conbuildmat.2008.05.006.

P. Cairney. Skid Resistance and Crashes - A Review of the Literature, ARRB Transport Research, Vermont, South - Australia, 1997 (311).

P. Geogiou, A. Loizos, A laboratory compaction approach to characterize asphalt pavement surface friction performance, Wear 311 (2014) 114-122. http://dx.doi.org/10.1016/j.wear.2013.12.028. 